Anuario del Instituto de Historia Argentina, vol. 17, nº 2, e052, diciembre 2017.

ISSN 2314-257X

Universidad Nacional de La Plata.

Facultad de Humanidades y Ciencias de la Educación.

Centro de Historia Argentina y Americana

\title{
Maternidades públicas y adopción legal en Córdoba, 1957-1974
}

\author{
Public maternity hospitals and legal adoption in Córdoba, 1957- \\ 1974
}

\section{Agostina Gentili}

CONICET, Universidad Nacional de Buenos Aires, Argentina | agosgentili@gmail.com

\section{PALABRAS CLAVE RESUMEN}

Historia social de la infancia

Poder judicial

Sistema de salud

Familia
Este artículo reconstruye el modo en que las maternidades públicas de la ciudad de Córdoba entregaban niños en adopción en los años sesenta. Para ello se recurre a la documentación enviada a las autoridades judiciales para legalizar aquellos actos de entrega: un conjunto de expedientes de los juzgados de menores sometidos a operaciones de cuantificación, reducción de la escala de observación y contextualización. Con foco en el juego de ponderaciones del que eran objeto el arbitrio asistencial y la convalidación judicial de esas entregas, se sostiene que esas experiencias de interacción permiten comprender rasgos emblemáticos del proceso de institucionalización de la adopción.

\section{KEYWORDS ABSTRACT}

Social history of childhood

Judicial branch

Health system

Family
This paper rebuilds the way in which public maternity hospitals in the city of Córdoba managed children's legal adoptions during the sixties. To do so, I have resorted to documents sent to judicial authorities to legalize placements acts; that is, a set of Juvenile Courts' files which have been quantified, reduced in scale for observation and contextualized. By looking at the set of arguments pondered in those assistential reasoning and judicial placement validation acts, I argue that those experiences of interaction allow us to comprehend emblematic features of the institutionalization of adoption processes. 


\section{Introducción}

En la Argentina de los años sesenta, la adopción era una opción jurídica reciente. Presente en la normativa colonial, el vínculo adoptivo no se incorporó en 1869 al primer Código Civil por considerase que no reflejaba las prácticas predominantes del país y que, en caso de desear alguien adoptar a un niño, podía acordar su entrega, criarlo y convertirlo en heredero ante un escribano público, esto es, hacerlo su hijo a través de un acto privado. Ello parecería confirmarse por los conocimientos disponibles sobre las prácticas familiares del período colonial y postcolonial del actual territorio argentino, que perfilan la existencia de una amplia difusión de entregas de niños en crianza con una escasa presencia de la adopción bajo la forma de un trámite judicial específico (Cicerchia, 1994; Ghirardi, 2008; Moreno, 2004; Seoane, 1989b, 1989a, 1990; Twinam, 2009). Para el orden normativo del naciente Estado nacional los hijos eran aquellos que devenían de la sangre, y sus circunstancias de nacimiento -marcadas por la existencia o no de una unión matrimonial de sus padres- definían los derechos que tendrían en el orden familiar. Una jerarquía jurídica de la filiación heredada del orden colonial que, con la constitución y difusión durante la primera mitad del siglo XX de un ideal uniforme y excluyente de familia -basado en la unión legal, heterosexual e indisoluble de la pareja y una asignación de roles según géneros y generación (Cosse, 2006; Míguez, 2006; Nari, 2004) -, acarrearía minusvalías sociales y simbólicas para quienes nacían de uniones "irregulares” (Cosse, 2007) .

La inexistencia jurídica de la adopción no había sin embargo inhibido su presencia como forma de constitución de las familias, experiencia de la que participaba incluso el propio Estado. Asilos y hogares infantiles entregaban niños con ese propósito y las autoridades judiciales contaban con un trámite particular para darles el apellido de quienes lo criaban como a un hijo. Estos procedimientos convivían con la opción, ilegal pero social e institucionalmente tolerada, de inscribir al niño como propio en el Registro Civil. Así lo evidencia Villalta (2012) en su estudio de las prácticas y nociones institucionales sobre la adopción de niños -presentes desde fines del siglo XIX en el escenario de Buenos Aires-, que configuraron las condiciones de posibilidad de las apropiaciones de niños de la última dictadura, y también la investigación de Flores (2004) sobre las prácticas de cesión de niños por parte de la Casa Cuna de Córdoba durante la primera mitad del siglo XX. La adopción presente ya en el abanico de experiencias familiares que con mayor frecuencia encontraban ocasiones de ser leídas en función de los parámetros normativos- se incorporaría al ordenamiento jurídico en 1948 (Ley $N^{\circ}$ 13.252) en un contexto en el que la omnipresencia de una sensibilidad favorable a la infancia atenuaba el peso de las discriminaciones sufridas por el historial familiar. Esto torcía décadas de iniciativas parlamentarias atoradas por la defensa católica de la "familia legítima”, tal como señaló Guy (inédito) al reconstruir los debates parlamentarios sobre la adopción, y Cosse (2006), en su investigación sobre las experiencias y los significados de la filiación “ilegítima” durante el primer peronismo. En aquella oportunidad, la adopción fue sancionada como un instrumento de protección de la infancia y una forma de dar hijos a quienes no podían tenerlos, pero también como una vía indirecta de reconocimiento de los “hijos ilegítimos” de quienes ya habían conformado una nueva familia tras una separación y no podían reconocer formalmente a sus hijos por la inexistencia del divorcio (Cosse, 2006; Villalta, 2012). Para que no atentara contra la “familia legítima” se creó un tipo de adopción conocida como simple, que no eliminaba la filiación biológica del niño y que sólo establecía un vínculo de parentesco con sus padres adoptivos -no con los miembros ascendentes y colaterales de esa familia-; además se definió que sólo el Estado, a 
través de sus autoridades judiciales, tenía la potestad de crearlo y revocarlo, hecho que desterraba el carácter de acuerdo entre particulares que la adopción tenía hasta entonces (Villalta, 2012) .

De tal manera, tanto estudios específicos sobre la adopción (Seoane, Flores, 2004; Guy, inédito y Villalta, 2012) como investigaciones que -abocadas a las dinámicas y convenciones familiaresofrecen referencias ocasionales sobre ella (Cicerchia, 1994; Ghirardi, 2008; Moreno, 2004; Twinam, 2009; Nari, 2004; Míguez, 2006 y Cosse, 2006) permiten vislumbrar que, en su extensa duración, lo que parecería haber mutado no es tanto la difusión de la adopción como práctica social sino la importancia que adquiere la legalización de las prácticas de cesión y acogimiento de niños con el avance de las instituciones del Estado en los distintos momentos del ciclo vital.

Desde 1957, en Córdoba, la potestad de crear el vínculo adoptivo recayó en los juzgados de menores $\underline{1}$. A partir de entonces, estas nuevas autoridades debieron granjearse el ejercicio efectivo de esa potestad que el mundo familiar y otras instituciones del Estado venían arbitrando por sus propios medios. En aquel contexto, buena parte de los abogados especializados en derecho de familia y los elencos institucionales de la minoridad afirmaban que la adopción simple era un tipo de adopción frágil que, al no extinguir por completo los lazos derivados del parentesco de sangre y ser revocable, brindaba pocas garantías a los adoptantes. A esa fragilidad se atribuía también la persistencia de las inscripciones falsas de niños en el Registro Civil, alternativa que permitía crear un vínculo completo de filiación que la adopción existente no establecía (Villalta, 2010) . Con esas consideraciones, en 1971 se sancionó una nueva normativa ( $\left.N^{\circ} 19.134\right)$ que incorporaba la adopción plena, es decir, un tipo no revocable de vínculo que sustituía al biológico, suprimía toda vinculación legal con la familia de sangre e incorporaba al niño a toda la red parental de sus padres adoptivos. Una jerarquización del vínculo adoptivo que procuraba hacer más atrayente el camino legal de esa forma de constitución de la familia.

Enmarcada entre la creación del fuero en la provincia y los primeros tres años de vigencia de la segunda ley de adopción del país, esta indagación procura conocer los rasgos asumidos por el proceso de institucionalización de la adopción legal de niños en Córdoba, al que entiende como un singular locus de observación de las modalidades asumidas por las relaciones entre el mundo familiar y el mundo estatal. Dicha relación impregna, aunque no siempre de manera explícita, buena parte de los aportes de la historia social de la infancia y la familia ( Hareven, 1995; Bjerg y Boixadós, 2004 ; Premo, 2008; Cosse, 2009; y Cosse et al., 2010). Este trabajo hace foco en uno de los principales escenarios institucionales de entregas en adopción, las maternidades públicas de la ciudad; se analiza su quehacer burocrático y las relaciones que mantenían con las autoridades judiciales a las que recurrían para validarlo.

Para ello aborda un conjunto de solicitudes de guarda con fines de adopción tramitadas en las secretarías de prevención de los juzgados de menores entre 1957 y 1974. La documentación forma parte del Fondo Documental Sección Menores del Centro de Documentación Histórica del Poder Judicial albergado en el Archivo General de los Tribunales de Córdoba -un conjunto de expedientes que iban a eliminarse, fueron rescatados y son hoy de acceso público $\underline{2}-$. Se trabaja con expedientes de guarda -trámite previo a la adopción- por tratarse de documentos que, en comparación con los expedientes de adopción, no sólo son más numerosos en el Fondo, sino que además ofrecen un mayor cúmulo de información sobre las circunstancias de entrega y acogida de los niños. El corpus 
en estudio está compuesto por 28 procesos labrados respecto de niños provenientes de las maternidades públicas, que serán puestos en relación con 57 solicitudes que involucraron otros escenarios de entrega ${ }^{3}$. A partir de un acercamiento que combina la cuantificación de prácticas y procedimientos con una lectura cualitativa de los procesos, la reconstrucción de aquellos arbitrios institucionales de entrega y sus convalidaciones judiciales se nutre de información proveniente de fuentes normativas, resoluciones de la Dirección General de Menores y el libro de actas de su Equipo Técnico de Adopción y Guarda. Una estrategia de indagación inspirada en los abordajes de fuentes judiciales de la historia social (Farge, 1991; Farge \& Revel, 1998), y de la historia y la antropología de la infancia y la familia (Cicerchia, 1994; Lugones, 2004; Twinam, 2009; Vianna, 2010) .

\section{Las maternidades en el concierto de escenarios de entrega}

El ordenamiento jurídico había depositado en la esfera judicial la potestad de otorgar la última palabra respecto de lo que sería considerado una entrega legítima, pero era una esfera creada y posicionada como el último eslabón de una cadena de instituciones que la precedían, no sólo en términos temporales sino también en las condiciones efectivas de gestión de las entregas. Veremos aquí que en estos años en que la adopción era una figura jurídica reciente, las familias y las instituciones del Estado compartían el arbitrio de una entrega en similares proporciones; la esfera judicial era entonces una instancia de legalización de actos tramados fuera de sus despachos. Elaborado a partir de las 85 solicitudes de guarda con fines de adopción identificadas, la tabla permite apreciar la existencia de una configuración descentralizada de entrega de niños como un rasgo emblemático del período. Poco más de la mitad de los niños provenía de instituciones del Estado y el restante conjunto de solicitudes -las más numerosas en términos absolutos- fueron presentadas por personas que habían recibido al niño de manera "privada”, a través de la madre, el padre, algún familiar o tercero.

Tabla 1. Situación en la que se encontraban los niños al pedirse sus guardas con fines de adopción

\begin{tabular}{|l|l|l|}
\hline & Cantidad & $\%$ \\
\hline Junto a sus guardadores & 38 & 45 \\
\hline En Maternidad Provincial & 15 & 18 \\
\hline En Maternidad Nacional & 13 & 15 \\
\hline En institutos de menores & 8 & 9 \\
\hline En Casa Cuna & 6 & 7 \\
\hline En Hospital de Niños & 4 & 5 \\
\hline En Hospital de Alta Gracia & 1 & 1 \\
\hline Total de niños & 85 & 100 \\
\hline & &
\end{tabular}

Fuente: elaboración propia a partir de 82 expedientes; AGTC, CDH, Fondo Menores. 
Las distintas frecuencias con que los niños salían de las instituciones con destino de adopción revela la preferencia que se tenía por las maternidades como lugares de búsqueda y el lugar marginal ocupado por los establecimientos de acogida y reclusión de niños, a pesar de haber sido estos últimos quienes más bregaron por la instrumentación de la adopción como solución al problema de la "infancia abandonada” y "potencialmente peligrosa”. Si a ello sumamos la notable presencia de niños que habían sido objeto de una entrega privada -o directa, como se la nombra hoy en la jerga tribunalicia-, la impresión que se tiene es que las leyes de adopción tuvieron poca incidencia entre las poblaciones infantiles sujetas a la potestad de las instituciones de minoridad. En todo caso, lo que despertaron fue una mayor disposición del mundo familiar a convalidar judicialmente acuerdos de entrega tramados en su seno. De cualquier modo, nada permite afirmar rotundamente que aquello que en la "narrativa judicial" 4 aparece como una entrega directa de la madre, el padre o algún familiar del niño a sus adoptantes, no involucra concertaciones de parteras o clínicas privadas, por ejemplo. De estas modalidades dan cuenta no sólo la investigación de Gesteira (2013) sobre las búsquedas de identidad emprendidas hoy por quienes fueron adoptados en el pasado reciente, sino también un amplio espectro de testimonios que circulan en redes sociales y periódicos, y también las experiencias de quienes colaboran con esas búsquedas en la Oficina de Derechos Humanos del Poder Judicial de Córdoba. Lo mismo puede sostenerse de las entregas en instituciones estatales, respecto de las cuales el relato judicial deja entrever la posibilidad de acuerdos previamente concertados entre la madre y los adoptantes.

Las maternidades públicas ocupaban un lugar predilecto entre los escenarios institucionales de entrega porque ofrecían la posibilidad de adoptar a un recién nacido, una preferencia del mundo familiar propia de casi todas las experiencias de entrega. El trasiego infantil que dejó sus rastros en la documentación judicial involucraba a niños en distintos momentos de su vida, pero aquel referido a la adopción tenía como principales protagonistas a bebés y niños que poco antes habían atravesado el umbral del lenguaje. La tabla 2 permite apreciar que al menos seis de cada diez niños eran bebés, poco más de dos tenían cuatro o menos años, y tan sólo uno de diez estaba ya en edad escolar.

Tabla 2. Edad de los niños al ser recibidos por sus guardadores

\begin{tabular}{|l|c|c|c|c|c|c|}
\hline & \multicolumn{2}{|c|}{ Mujeres } & \multicolumn{2}{c|}{ Varones } & Subtotal & $\%$ \\
\hline & Cantidad & $\%$ & Cantidad & $\%$ & & \\
\hline Días & 11 & 25 & 9 & 22 & 20 & 24 \\
\hline Meses & 18 & 41 & 16 & 39 & 34 & 40 \\
\hline 1 a 4 años & 10 & 23 & 10 & 25 & 20 & 24 \\
\hline 5 a 9 años & 5 & 11 & 5 & 12 & 10 & 11 \\
\hline Sin referencias & & & 1 & 2 & 1 & 1 \\
\hline Total de niños & 44 & 100 & 41 & 100 & 85 & 100 \\
\hline \multicolumn{7}{|c|}{ Fuente: elaboración propia a partir de 82 expedientes; AGTC, } \\
CDH, Fondo Menores. \\
\hline
\end{tabular}


El análisis de las formas asumidas por el arbitrio institucional de la entrega y las prácticas judiciales de su convalidación devela otros aspectos involucrados en ese lugar privilegiado que ocupaban las maternidades entre los escenarios institucionales de la adopción. El ordenamiento jurídico había depositado en la esfera judicial la potestad de otorgar la última palabra respecto de lo que sería considerado una legítima entrega en adopción, sin definir para ello un procedimiento específico. En los juzgados de menores se apelaba al procedimiento genérico estipulado para los procesos que involucraban a niños sin conflicto con la ley penal: la intervención de un asesor de menores, la realización de un informe técnico (una encuesta ambiental y familiar que realizaban las asistentes sociales de la Dirección General de Menores, órgano de colaboración de los juzgados), y la realización de una audiencia previa al dictado de la resolución $\underline{\underline{5}}$. Este repertorio de pasos burocráticos estaba destinado a ponderar los méritos de quienes deseaban quedarse con el niño que ponía de relieve que las autoridades judiciales contaban con la potestad de legalizar esas entregas pero no aún de arbitrarlas. Ese recorrido de acciones gravitaba sobre los procesos sin que la ausencia de alguno de sus pasos modificara el destino de los niños, ya definido al pedirse la guarda. Como veremos, estos pasos se desplegaban selectivamente, y dependían en gran medida de los escenarios en que había tenido lugar la entrega.

El 26 de agosto de 1970 la Maternidad Nacional comunicaba al juez de menores que allí "se encontraba abandonada la niña C. B. Ochoa nacida el $1^{\circ}$ de agosto del corriente año, cuya progenitora firmó consentimiento para que fuera dada en adopción”, y presentaba a un matrimonio de "referencias óptimas”. Enviaba a continuación una serie de certificados: de inscripción de la niña en el Registro Civil; de domicilio, salud, esterilidad y buena conducta de cada miembro de la pareja; otro de ella, como “maestra de grado”, y una “manifestación de bienes”. Al día siguiente el matrimonio se presenta a uno de los juzgados a pedir la guarda con fines de adopción, se la otorgaban de manera provisoria, se oficiaba a la Maternidad para la entrega y se notificaba al asesor de menores $\underline{6}$.

Un mes más tarde llegaba al juzgado una comunicación de la Maternidad Provincial informando que allí se encontraba internada una niña cuya madre habría "dejado en abandono en servicio social desde su nacimiento”. Acompañaban esta nota certificados de inscripción de la niña, de salud, domicilio y buena conducta del matrimonio interesado en su adopción, de esterilidad de la mujer y de trabajo de su esposo - “operario calificado de FIAT”-, recabados un mes antes del nacimiento de la niña. Se enviaba también el acta de renuncia que la progenitora firmara a los dos días del nacimiento de su hija, un escrito a máquina que no superaba los seis renglones, en el que decía dejarla a cargo del servicio social "por razones familiares y económicas" para que fuera dada en adopción “en la forma en que se creyera conveniente”. Ese mismo día el matrimonio se presentaba en el juzgado a pedir la guarda; el asesor de menores decía no tener nada que objetar y olvidaba consignar su nombre en el expediente; la guarda se les concedía por decreto con carácter provisorio y se oficiaba a la Maternidad para su entrega. Ésas eran todas las actuaciones ${ }^{7}$.

Como muestran ambos relatos judiciales, los servicios sociales de las maternidades contaban con un procedimiento específico de entrega que involucraba la presentación de quienes deseaban adoptar al niño a las autoridades judiciales y la confección de un acta de renuncia en la que la madre dejaba asentado "su deseo" de darlo en adopción $\underline{-}$. Los matrimonios se inscribían en los listados de 
adoptantes del servicio social, se les hacía un informe ambiental y familiar que solía conservarse en los ficheros de la repartición -sólo dos fueron incorporados a sus respectivos expedientes judiciales $\underline{9}-$, y tenían que presentar una serie de documentos que avalaran su "solvencia material y moral”. Tras conocer a los niños iban al juzgado a pedir la guarda con esa documentación y una nota institucional que informaba la situación. La guarda se les confería por decreto y con carácter provisorio en ese mismo acto, para regresar luego a las maternidades a buscar a los niños e iniciar así una nueva vida en familia.

En la mayoría de las ocasiones en que los niños provenían de las maternidades, el episodio judicial de sus entregas se resolvía, así, en un único acto de cuatro pasos procesales: solicitud de la guarda, concesión provisoria por decreto, notificación a la asesoría y orden de entrega. Se prescindía de la realización de encuestas ambientales y familiares por parte de las asistentes sociales de la Dirección General de Menores, de la celebración de audiencias y del dictado de autos interlocutorios $\underline{10}$, como así también de la indagación de las circunstancias que habrían llevado a las madres a entregar a sus hijos; bastaban para ello las actas de renuncia o las comunicaciones enviadas desde las maternidades. Estamos en presencia de una modalidad de entrega que no sólo pone de relieve que los juzgados dejaban en manos de los servicios sociales de las maternidades la indagación de las circunstancias de cesión y acogimiento de esos niños, sino también que la guarda provisoria por decreto era suficiente para iniciar, años después, el juicio de adopción. Sabemos que esto último era habitual entre 1975 y 1983는 Para el período en estudio lo confirman la recurrencia de procesos resueltos en esa única instancia y el hallazgo de uno en el que, a tres años de su inicio, las autoridades certifican que la niña había sido adoptada en el fuero civil $\underline{12}$.

Tabla 3. Procedimientos de guarda con fines de adopción según escenario de entrega del niño a sus guardadores 


\begin{tabular}{|c|c|c|c|c|c|c|c|c|c|c|c|c|}
\hline \multirow[t]{2}{*}{$\begin{array}{l}\text { Actuaciones / Escenario de } \\
\text { entrega }\end{array}$} & \multicolumn{2}{|c|}{$\begin{array}{l}\text { Maternida } \\
\text { des } \\
\text { públicas }\end{array}$} & \multicolumn{2}{|c|}{$\begin{array}{l}\text { Hospital } \\
\text { de Niños y } \\
\text { de Alta } \\
\text { Gracia }\end{array}$} & \multicolumn{2}{|c|}{ Casa Cuna } & \multicolumn{2}{|c|}{$\begin{array}{l}\text { Institutos } \\
\text { de } \\
\text { menores }\end{array}$} & \multicolumn{2}{|c|}{$\begin{array}{l}\text { Entregas } \\
\text { "privadas }\end{array}$} & \multirow[t]{2}{*}{ Subtt. } & \multirow[t]{2}{*}{$\%$} \\
\hline & Cant. & $\%$ & Cant. & $\%$ & Cant. & $\%$ & Cant. & $\%$ & Cant. & $\%$ & & \\
\hline $\begin{array}{l}\text { Participación de la asesoría de } \\
\text { menores }\end{array}$ & 19 & 68 & 4 & 80 & 6 & 100 & 8 & 100 & 31 & 82 & 68 & 80 \\
\hline $\begin{array}{l}\text { Sin participación de la asesoría } \\
\text { de menores }\end{array}$ & 9 & 32 & 1 & 2 & & & & & 7 & 18 & 17 & 20 \\
\hline $\begin{array}{l}\text { Encuesta ambiental y familiar en } \\
\text { casa de los guardadores } \\
\text { ordenada por el juzgado }\end{array}$ & 6 & 21 & & & 2 & 33 & 6 & 75 & 25 & 66 & 39 & 46 \\
\hline $\begin{array}{l}\text { Encuesta en casa de los } \\
\text { guardadores a cargo del } \\
\text { Servicio Social de la maternidad } \\
\text { o el hospital }\end{array}$ & 2 & 7 & 1 & 20 & & & & & & & 3 & 4 \\
\hline $\begin{array}{l}\text { Encuesta en casa de los } \\
\text { guardadores y progenitores o } \\
\text { familiares del niño ordenada por } \\
\text { el juzgado }\end{array}$ & & & 3 & 60 & 1 & 17 & 1 & 13 & 9 & 24 & 14 & 16 \\
\hline $\begin{array}{l}\text { No consta realización de } \\
\text { encuesta }\end{array}$ & 20 & 72 & 1 & 20 & 3 & 50 & 1 & 13 & 4 & 10 & 29 & 34 \\
\hline Audiencia & 8 & 29 & 1 & 20 & 1 & 17 & 5 & 63 & 24 & 63 & 39 & 46 \\
\hline Sin realización de audiencia & 20 & 71 & 4 & 80 & 5 & 83 & 3 & 37 & 14 & 37 & 46 & 54 \\
\hline $\begin{array}{l}\text { Guarda concedida por decreto al } \\
\text { inicio o durante el transcurso del } \\
\text { proceso }\end{array}$ & 20 & 72 & 4 & 80 & 4 & 66 & 4 & 50 & 12 & 32 & 44 & 52 \\
\hline Guarda por auto interlocutorio & 8 & 28 & 1 & 20 & 1 & 17 & 4 & 50 & 20 & 52 & 34 & 40 \\
\hline $\begin{array}{l}\text { No se concede por desistir los } \\
\text { guardadores }\end{array}$ & & & & & & & & & 3 & 8 & 3 & 3 \\
\hline No consta concesión de guarda & & & & & 1 & 17 & & & 3 & 8 & 4 & 5 \\
\hline Total de solicitudes & 28 & 33 & 5 & 6 & 6 & 7 & 8 & 9 & 38 & 45 & 85 & 100 \\
\hline
\end{tabular}

Como permite apreciar el cuadro 3, dos tercios de estas 28 solicitudes se resolvieron en aquel único episodio judicial de cuatro pasos que involucraba la concesión provisoria de la guarda al inicio de las actuaciones, al tiempo que sólo un tercio de los guardadores fueron encuestados por la Dirección General de Menores y convocados a la audiencia de ley, para que luego se les concediera la guarda a través de un auto interlocutorio. Este escueto procedimiento de rutina mostraba que las autoridades judiciales tenían una particular confianza en los arbitrios que hacían las maternidades, confianza que puede dimensionarse al comparar estos procedimientos con aquellos que se desplegaban cuando los niños provenían de los restantes escenarios de entrega. En estas ocasiones, el despliegue procesal no seguía un recorrido tan claro, sintético y específico. Al interior de esa diversidad se observa que la gran mayoría de las solicitudes son concedidas y que los procedimientos se dirigen ante todo hacia la evaluación de los guardadores a través de las encuestas ambientales y familiares encomendadas a la Dirección de Menores. Esto sucedía en un degradé signado por la existencia o no de una previa participación de los servicios sociales ajenos al campo 
de la minoridad, esto es, de la salud o la Casa Cuna, que por cierto en esos años estaba iniciando su proceso de especialización como institución hospitalaria $\underline{13}$. En otras palabras, en una época en que las familias y las instituciones estatales compartían la posibilidad de arbitrar entregas en adopción, las energías judiciales de convalidación se dirigían hacia el mundo familiar, desplegando una actitud de menor control sobre los arbitrios institucionales.

Ahora bien, las formas asumidas por la intervención judicial en las oportunidades en que eran las Maternidades públicas las que abrían el camino a la adopción también dependían de las circunstancias en que se encontraban los niños; entiendo que es justamente este aspecto el que permite comprender las diferencias entre los procedimientos judiciales desplegados tras intervenciones de las maternidades. Éstas fueron también un escenario de entrega de bebés que allí se llevaban tras haber sido encontrados en la vía pública. En estas ocasiones, la elección de los guardadores no necesariamente recaía en sus servicios sociales. En marzo de 1967 y febrero de 1973 dos recién nacidas ingresaron en la Maternidad Nacional tras haber sido encontrada la primera por un hombre en la entrada de una casa deshabitada en uno de los barrios más ricos de la ciudad, y la segunda por un policía en un pasaje cerrado al tránsito vehicular cercano al Hospital de Niños. Tras actuaciones policiales comunicadas por la Maternidad, la primera niña salía en guarda junto con un matrimonio escogido por el servicio social de la institución, un mes después de haber sido encontrada con "signos de prematuridad, cianosis generalizada, baja temperatura corporal y dificultad respiratoria", lo que constituye el aspecto propio de "una recién nacida de aproximadamente 10 horas de vida” $\underline{14}$. En el segundo caso, la niña había sido encontrada por un agente de policía que escuchó los "vagidos y llantos característicos de un niño de muy corta edad” en aquel pasaje, “envuelta con trapos viejos y prácticamente tapada por los yuyales”.

Con la premura del caso y como primera medida -continuaba el relato sumarial- el agente actuante la trasladó hasta el Hospital de Niños distante a pocos metros, donde la niñita recibió por parte de los facultativos de guardia la atención médica del caso, determinándose que tendría entre 5 y 6 días de vida, siendo su estado de salud en general bueno, aunque de bajo peso, por lo que, y en razón de su edad, se hacía imprescindible su internación en un servicio de puericultura (...) quedando en consecuencia la criatura internada en la Maternidad Nacional. Pese a la búsqueda efectuada por el empleado interviniente en el lugar del hecho y sus inmediaciones, no se encontró carta ni otro indicio de utilidad a los fines de la investigación correspondiente.

Así se enteraba el juzgado de las circunstancias en que había sido encontrada esa niña, a través de una comunicación que esta vez provenía directamente de la policía y era recibida en las oficinas judiciales el mismo día en que un miembro de la fuerza y su esposa pedían la guarda con fines de adopción. Sumados a ese, otros indicios hacen suponer que en esa ocasión fue la policía y no el servicio social la que escogió a los guardadores. Todo parece indicar que, de haberlo hecho la Maternidad, el juzgado no habría pedido la realización de la encuesta ambiental y familiar al matrimonio, ni la jefa del servicio social habría tenido que presentarse días después a explicar "los motivos que la llevaron a no entregar a la criatura, sin ánimo de faltar a la orden del tribunal”쓰.

Las historias de estas niñas permiten entrever dos cuestiones. En primer lugar, que el abandono de los niños en espacios públicos o la puerta de una casa era sumamente excepcional en aquellos años: 
sólo ellas dos y otra recién nacida encontrada en 1974 en la puerta de la casa de una mujer que pidió su guarda $\frac{16}{}$ vivieron episodios como aquellos. Si, al decir de Moreno, el abandono de niños en la vía pública era "sistemático" en la sociedad porteña de finales del siglo XVIII y principios del XIX (2004, pp. 92-93), la excepcionalidad de esa experiencia entre los procesos en estudio anima a pensar que en la sociedad contemporánea adquirió el carácter -en términos de Williams (2009) - de un rasgo residual de la cultura, esto es, dejó de ser un componente dominante para manifestarse como una herencia del pasado. Por otra parte, desde la perspectiva de Elias (1998) podría sostenerse que aquella excepcionalidad estaría dando cuenta de una modificación en los umbrales de sensibilidad en las relaciones entre padres e hijos, esto es, que los progenitores de niños no deseados o de niños que no podían cuidar estaban muy poco dispuestos a recurrir a esa forma de abandono que podía poner en peligro la vida de sus hijos. En segundo lugar, los relatos judiciales de esas entregas revelan que aquellas circunstancias que la legislación reconocía como competencia específica de los juzgados de menores tenían sólo un alcance jurídico: los procedimientos policiales y asistenciales se anticipaban a la injerencia judicial en grado tal, que a ésta sólo restaba la convalidación de las resoluciones desplegadas por aquellas esferas.

En sólo dos ocasiones pareciera ser el juzgado el que escogió a los guardadores de niños provenientes de maternidades. En septiembre de 1962, una niña hacía seis meses que estaba internada en el Instituto de Puericultura de la Maternidad Nacional. Según el servicio social no había sido inscripta en el Registro Civil y sus padres la habían visitado en una única ocasión. El servicio social intentó internarla en la Casa Cuna o entregarla a una familia, no lo consiguió y solicitó entonces la "valiosa intervención” del juzgado. Siete días más tarde una mujer pidió su guarda y la niña se fue con ella. En octubre llegaba un favorable informe de la encuesta ambiental y familiar realizada por una asistente social de la Dirección General de Menores, y es ésa la última actuación del expediente $\frac{17}{}$. La segunda ocasión en que parecieran haber sido las autoridades judiciales las que escogieron a los guardadores tuvo lugar en 1965. El 4 de noviembre la Maternidad Provincial informaba que en la madrugada del 31 de octubre "ingresaba con trabajo de parto una persona que decía llamarse [...], casada, argentina, de 26 años, domiciliada en [...], dando a luz a un niño de sexo femenino de 3.480 gramos, tez mate, cabello oscuro, que no presentaba señas particulares", quien "en horas de la tarde [...] había abandonado la Maternidad desconociéndose el momento y la hora”, no pudiendo el servicio social "localizar a la prófuga con los datos que se conocían”. La comunicación era recibida al día siguiente en el juzgado y sus autoridades pedían a la policía que citara a la progenitora "bajo apercibimiento de ley”. Esta diligencia fue infructuosa según la comunicación policial recibida dos días después: no existía la dirección dejada por la progenitora en los registros de la Maternidad y en la zona era una persona desconocida. Al día siguiente, un matrimonio pedía la guarda de la niña, la cual se le otorgaba de manera provisoria oficiándose su entrega a la Maternidad. Dos años más tarde, tras haber sido citados los guardadores y haberse asentado que "la niñita estaba bien con ellos y que iniciarían la adopción cuando se cumpliera el término legal”, se ordenaba el archivo de las actuaciones $\frac{18}{\text {. La }}$ primera de estas experiencias pone en relieve que las maternidades dejaban en mano de los juzgados una ubicación para los niños sólo cuando ya habían agotado sus propias opciones de derivación -algo que, como vemos, raras veces ocurría- al tiempo que ambos procesos evidencian que los arbitrios judiciales del destino de un niño no eran explicitados en los expedientes: la 
narrativa judicial no permite reconocer de qué manera los juzgados tenían conocimiento de los matrimonios que deseaban adoptar o criar a un niño.

Los procedimientos de guarda avanzaban más allá de la concesión provisoria por decreto al inicio de las actuaciones; se realizan encuestas ambientales y familiares por parte de las asistentes sociales de la Dirección General de Menores, se celebraban audiencias y se concedían guardas definitivas a través de autos interlocutorios, no sólo en las infrecuentes ocasiones en que los matrimonios no eran presentados por las maternidades, sino también cuando las madres eran menores de edad o comunicaban personalmente su decisión de dar a sus hijos en adopción. Lo primero sucedió en tres ocasiones, en las que las progenitoras se presentaron a manifestar su renuncia y la conformidad con la adopción; una de estas jóvenes lo hizo junto a la abuela materna del niño, quien prestó a su vez conformidad con la decisión que habría tomado su hija $\underline{19}$.

Lo segundo ocurrió en una única ocasión con una cronología procesal que deja entrever la posibilidad de que al momento de la renuncia aún no se sabía quiénes serían los guardadores. La madre del niño se presentó en el juzgado el 3 de abril de 1974, a los cinco días de haber dado a luz, "renunciando a todos sus derechos que como madre le correspondían y estando en conocimiento de las consecuencias de ese acto”, pero el matrimonio que pidió su guarda lo hizo un mes después, avalado por una nota de la Maternidad y con los certificados recabados entre el 19 de abril y el 2 de mayo, es decir, dos semanas después de la renuncia materna ante el juzgado y un día antes de la solicitud de guarda $\underline{20}$. Como en esta oportunidad la Maternidad sólo presentaba al matrimonio y mencionaba que el niño había sido “dejado en abandono en servicio social para su adopción”, no sabemos qué pudo haber demorado su salida. Las autoridades hospitalarias solían requerir a los juzgados soluciones urgentes para los niños abandonados tras sus nacimientos o internaciones, porque su permanencia suponía la ocupación de una cama o cuna en un foco latente de enfermedades, un ambiente que no podía garantizar los cuidados necesarios. Quizá aquel niño tuviera algún problema de salud o algún “defecto” de nacimiento (como se decía) que lo hacía poco atractivo a los ojos de quienes deseaban adoptar. Así ocurrió en una oportunidad en que las autoridades judiciales convalidaron la entrega de un niño nacido en la Maternidad Provincial a un matrimonio que la institución presentaba pero que no formaba parte de sus listados de adoptantes. Era septiembre de 1970 cuando se informaba que el niño estaba internado desde su nacimiento, ocurrido un mes atrás; se adjuntaba un resumen de su historia clínica "para una mayor comprensión de la situación” y se presentaba a un matrimonio interesado en su adopción al cual, “dadas las circunstancias”, se aconsejaba que se le concediera la guarda. Entre otros aspectos, aquel resumen de la historia clínica decía que había sido el primer parto de una mujer sana de 22 años, "paciente de regular estado de nutrición” que no había recibido atención médica durante el embarazo. El bebé no había llorado al nacer y estuvo "60 minutos” sin respirar; había ingresado al servicio de neonatología en "grave estado" con un “diagnóstico final” de daño cerebral. Cuando el matrimonio se presentó en el juzgado a pedir la guarda, la mujer explicó que "no le importaba” que el niño estuviera “enfermo", que ella estaba “decidida a tenerlo igual”, que como en la Maternidad no podían tenerlo, “una enfermera lo había sacado en guarda unos días y ella lo conoció en su casa y se encariñó, por lo que lo tenían en su hogar desde el viernes pasado, estando dispuesta a brindarle un hogar”. La determinación era tal que ya le habían escogido un nombre: con ese nombre y el apellido 
del guardador se caratulaba el expediente cuya primera actuación fuera la concesión provisoria de la guarda, y su segunda y última, la notificación a la asesoría de menores 21 . Una experiencia que, justificada por la gravedad de la salud del niño, habilitaba la explicitación de acciones expeditivas de entrega -de la salida temporaria del niño junto a una enfermera al conocimiento en esa circunstancia de quien sería su guardadora-, las cuales bien podrían haber existido en otras ocasiones.

La situación podía no ser tan grave como la de aquel bebé, pero podían existir circunstancias de nacimiento que demoraran la salida de los niños de las maternidades tras la renuncia o el abandono de sus progenitoras. En una ocasión, la Maternidad Nacional informaba al juzgado que un niño de siete meses había sido "abandonado por su progenitora”, “un bebé prematuro que nació con un peso de 1.200 gramos" que "no había salido a su debido tiempo dado que su aspecto físico poco favorable provocaba la no aceptación de los numerosos matrimonios que se citaron”. En la misma nota presentaban al matrimonio que quería adoptarlo, cuyos cónyuges ese día eran nombrados guardadores provisorios a través del ya mencionado único acto judicial de convalidación de la entrega $\underline{22}$.

Llegado este punto, se imponen algunas observaciones adicionales relacionadas con el tiempo transcurrido entre el nacimiento del niño y los trámites que hacían los matrimonios para reunir la documentación que les pedía el servicio social. Si se tiene en cuenta la actualidad que debía poseer la documentación que se presentaba para acreditar "solvencia material y moral”, una diferencia de días posteriores al nacimiento sugiere que los matrimonios tuvieron noticia del niño en ese momento, lo que al parecer era lo más frecuente $\frac{23}{}$. Que la documentación fuera recolectada días o meses antes del nacimiento del niño permite inferir al menos tres posibilidades: que la espera entre la inscripción en las listas y la entrega del niño no era larga -lo que contradiría algunos relatos de las encuestas ambientales y familiares ${ }^{24}$-; que el servicio social supo durante los controles prenatales que la madre entregaría a su hijo en adopción; que los matrimonios podían haber conocido por su cuenta a la madre, y que tales arreglos particulares eran aceptados por los servicios sociales $\underline{25}$.

\section{La construcción de sentidos sobre la adopción}

Salvo por aquellas cuatro situaciones en que las madres renunciaron a sus hijos ante las autoridades del fuero, los relatos judiciales de las entregas de niños provenientes de las maternidades muestran que las renuncias o las búsquedas siempre infructuosas de las progenitoras solían estar a cargo de los servicios sociales y no del juzgado $\underline{\underline{26}}$. Ambas situaciones, la de una renuncia por escrito y la del abandono, dejaban sin embargo librado al contexto los posibles significados de esos actos: las renuncias, porque apelaban a una fórmula genérica -“dejo a mi hijo por razones económicas y familiares para que el servicio social lo entregue en adopción”-; los “abandonos”, porque no dejaban rastro alguno de las razones que habrían llevado a esas madres a desprenderse de sus hijos $\underline{27}$. Un trasfondo de entrega que terminaba siendo aún más opaco al constatarse que las maternidades solían recurrir a la noción de abandono al informar tanto una como otra circunstancia ${ }^{28}$. 
Investigaciones sobre las prácticas y nociones construidas por los circuitos asistenciales, asilares y judiciales de la minoridad desde finales del siglo XIX concuerdan en señalar el uso indiscriminado de la noción de abandono por parte de un variado espectro de elencos institucionales. En su análisis de las disputas entre defensorías de menores, congregaciones religiosas y la Sociedad de Beneficencia de Buenos Aires, entre finales del siglo XIX y principios del XX, Villalta sostiene que en aquel “contexto de producción de perdurables categorías” la niñez “abandonada” se constituyó como problema socialmente relevante no por el aumento efectivo del abandono sino por la percepción y la interpretación moral que las élites tenían al respecto. El abandono se forjó como recurso argumental de dichas élites para demandar la ampliación de sus facultades; en otras palabras, la construcción de la noción de abandono fue instrumental a la construcción paralela de la legitimidad del accionar de aquellos actores (2012, pp. 61-66). Así, la noción de abandono infantil imperante durante el siglo XX ya no remitía sólo a su sentido literal (el niño abandonado en el pórtico de una iglesia o la puerta de una casa), sino a lo desatendido, lo descuidado, y ambos términos eran desde entonces sinónimos de una “irresponsabilidad” parental. De allí que, cuando esta categoría fraguada por el quehacer de las instituciones y sus agentes tomó forma jurídica con la sanción en 1919 de una ley que modificaba los criterios de patria potestad -se definía no sólo como el conjunto de derechos sino también de obligaciones de los padres hacia sus hijos, y se habilitaba la tutela estatal cuando éstas se incumplían $\underline{29}$-, la noción de abandono fue acompañada por los

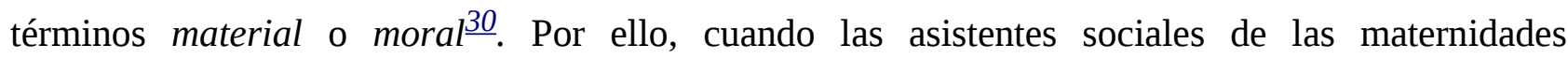
catalogaban las entregas en adopción como abandono -sin discriminar las ocasiones en que las madres renunciaban a sus hijos de aquéllas en las que se “fugaban”-, más que describir la situación en la que se encontraban los niños, daban cuenta de los significados que ellas, al igual que otros agentes estatales, atribuían a esas entregas. Por encontrarse desperdigada entre las más disímiles situaciones y por convivir en un mismo relato junto al "deseo" de la madre de dar a su hijo en adopción, la asociación entre entrega y abandono pierde fuerza explicativa y se perfila más como una fórmula de la comunicación burocrática que como una descripción de las circunstancias.

Algo similar aparecía cuando ese juego de solapamientos operaba sobre los orígenes sociales de los niños. Si bien este aspecto mereció un análisis más detallado en otro artículo (Gentili, 2017), es importante señalar que la narrativa judicial era comúnmente elusiva al momento de explicar quiénes y por qué entregaban a un niño en adopción. Las madres que con mayor nitidez aparecen eran jóvenes, solteras, pobres y estaban solas, pero cuándo, cómo y con quién quedaron embarazadas eran rastros que raras veces formaban parte de la narrativa judicial, tanto más cuando los niños provenían de las maternidades, en cuyo caso no existía referencia alguna a las experiencias personales que habrían desencadenado la entrega en adopción. Durante la primera mitad del siglo XX estos escenarios habían sido responsables de la construcción de dos representaciones contrapuestas de la maternidad soltera (Biernat y Ramacciotti, 2008; Billorou, 2007; Di Liscia, 2002; Nari, 2004). Por un lado, las madres solteras eran asociadas a las altas tasas de mortalidad infantil y el escaso crecimiento poblacional, como así también al abandono y la internación de niños. Por el otro, difundieron también la imagen de esas mujeres como "doblemente madres", en la medida en que incluso en situaciones de pobreza y desamparo afrontaban con altruismo, sacrificio y abnegación el nacimiento y la crianza de un hijo sin padre. Ahora bien, si nos quedamos sólo con aquello que se explicita en estas fuentes, todo pareciera indicar que únicamente las mujeres pobres 
entregaban a sus hijos en adopción. Sin embargo, en ocasiones sólo quedaron registrados sus nombres sin referencias a las circunstancias que vivían. Este vacío, sin llegar a colmado, podríamos llenarlo con las palabras del director de la Maternidad Provincial, quien sostenía que junto a las empleadas domésticas "instigadas por sus patrones y el problema laboral que se les presentaba", uno de los casos más comunes de entrega era el de las "estudiantes universitarias embarazadas y rechazadas por sus familias y la sociedad” $\underline{1}$. Cuesta creer que en los juzgados no conocieran esas experiencias, pero como nunca dejaron rastros de ellas en los expedientes es posible pensar en la posibilidad de que ante ellas imperara la reserva. Lo que así se perfila es una política burocrática del reconocimiento de los orígenes sociales de estos niños, tendiente a reforzar tanto las diferencias de género que pesaban sobre la sexualidad no conyugal como el prejuicio que hacía, tanto de la maternidad soltera como de la entrega de un niño en adopción, un asunto de las clases populares.

Esas veladuras eran las que, por otra parte, delineaban la adopción formal como una experiencia de ascenso social. Cuando el Estado tenía la posibilidad de escoger a los guardadores -algo que ocurría en los casos en que las maternidades y otros ámbitos de la salud eran los escenarios de entregaelegían a parejas casadas sin hijos ni posibilidades de tenerlos, que gozaban de una buena posición económica gracias al salario del varón que permitía a la mujer dedicarse a las tareas de la casa y al cuidado del niño. La pareja recibía a un bebé recién nacido, de seis meses a lo sumo, con quien no tenían ningún vínculo de parentesco biológico ni social, de manera tal que la conformación de la familia adoptiva era homóloga a la conformación de la "familia legítima", y el relato judicial de la adopción versionaba el ideal hegemónico de la familia argentina del siglo XX, es decir, un modelo de la domesticidad que los estratos medios consideraban como propio y funcionaba como parámetro de lectura y ponderación de las diversas formas de organización familiar existentes, signo del ascenso social y simbólico de las clases populares (Cosse, 2006, 2010; Míguez, 2006; Nari, 2004) . Esa homogeneidad de las configuraciones familiares a las que arriban los niños tras un arbitrio en manos de los servicios sociales de la salud contrastaba con la mayor diversidad que presentaban las familias adoptivas conformadas a partir de las entregas privadas o la salida de los niños de un instituto de menores. En estas ocasiones, los niños llegaban a familias ya constituidas o monoparentales con hijos propios nacidos de uniones tanto consensuales como matrimoniales y menos aventajadas en términos económicos $\frac{32}{2}$. Si al carácter obrero de las familias de destino sumamos la reserva que imperaba al momento de dar cuenta de otros orígenes familiares que no fueran los populares, cabría pensar que no todos esos niños habrían pasado de una familia pobre a una con mejores ingresos. Incluso al constatarse que la mayoría de las situaciones en que los niños fueron adoptados por familias de clases medias consolidadas provenían de las maternidades -allí donde se reconocía que las “estudiantes” entregaban a sus hijos-, en todo caso el cambio de estatus filial podía suponer no una experiencia de ascenso social del niño, sino de permanencia. Tanto una como otra posibilidad estaban ante todo en manos del servicio social que escogía a los adoptantes, de modo que no resulta absurdo pensar que fuera un criterio de clase el que haya orientado la asignación de tal niño a tal matrimonio.

\section{Primeros pasos hacia la centralización de las entregas en adopción}

Aquella diversidad de escenarios, procedimientos y familias de destino fueron condiciones que 
desembocaron en los primeros pasos hacia la centralización institucional de la adopción, dados en Córdoba en 1972 con la creación del Equipo Técnico de Adopción y Guarda de la Dirección

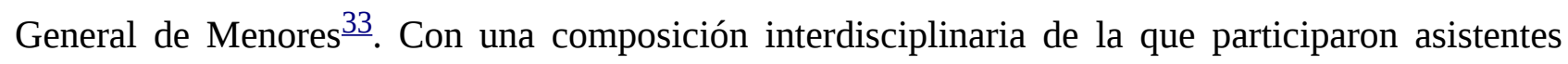
sociales, médicos, abogados, psicólogas y psicopedagogas $\frac{34}{4}$, al equipo se le encomendó la evaluación de los niños internados para determinar quiénes estaban en condiciones de regresar al ámbito familiar, propio o ajeno, y la unificación de criterios de entrega y pautas a seguir para el registro y la selección de los guardadores, no sólo con las maternidades públicas, la Casa Cuna y el Hospital de Niños, también con las diversas instancias de la propia Dirección de Menores (jefes de departamento, directores y personal de los institutos). Se celebraron así reuniones en las que, entre otras cosas, se habló de la necesidad “de un estudio completo de los matrimonios” con "un criterio uniforme” de confección de los informes, y de la existencia de "un solo lugar” para recibir los pedidos de guarda, al que cada servicio social derivaría la documentación del caso $\underline{35}$.

Era la primera vez que una repartición ideada varias décadas atrás para supervisar la circulación institucional de niños contaba con un área singular abocada a los destinos infantiles hogareños. La iniciativa sería una antesala de lo que en la década del '80 acabaría por cristalizar en equipos técnicos y listados únicos de adoptantes de tribunales. La voluntad de unificación de criterios institucionales de entrega fue sin embargo incipiente y no pareciera haber sido decisiva. La tarea estuvo a cargo de un equipo que se encontraba ante un desafío que tenía que enfrentar con pocos recursos de personal, sin un espacio propio de trabajo, con escasos días disponibles para reunirse y con una posición subordinada dentro de la repartición, lo que menguaba la observancia de sus recomendaciones tanto en el frente interno como en el externo. Este equipo debía no sólo legitimar la importancia de sus propósitos ante otras instituciones, sino también ante el amplio abanico de instancias y dependencias de la propia Dirección de Menores $\underline{36}$.

Hacia fines de 1974, el ímpetu inicial de esta instancia de coordinación mostraba claros signos de deterioro. Sus miembros eran cada vez menos porque otras dependencias de la repartición exigían sus labores, muchas de sus reuniones dejaron de celebrarse y se interrumpió el trabajo en equipo por "problemas institucionales" que "no pudieron ser superados". El golpe de Estado provincial de febrero de aquel año había traído nuevas autoridades que, con criterios diferentes, brindaron un escaso apoyo a la labor que venían realizando $\underline{37}$. A juzgar por el tenor y la languidez del contenido de las reuniones que celebraron a partir de entonces, la inestabilidad política del país y el clima crecientemente autoritario que imperaría en la repartición pública y la vida ciudadana tras el golpe de Estado de 1976 terminó abatiendo (también) esta primera y tenue iniciativa de centralización estatal de las entregas de niños en adopción. Cabe pensar también que aquella experiencia de centralización no sólo perdió fuerza por la coyuntura vivida, sino que tampoco la habría recuperado con el regreso de la democracia en 1983, porque a partir de entonces fue el poder judicial el que tomó las riendas de ese propósito, creando sus propios equipos técnicos y listados de adoptantes, y avanzando así sobre una potestad que desde el principio había disputado a la esfera administrativa de la minoridad.

\section{Conclusiones}

En el concierto de escenarios en que tenían lugar las entregas de niños en adopción en los años 
sesenta, las maternidades públicas son presentadas en la narrativa judicial como un escenario predilecto para los distintos actores en escena, por un lado, para los guardadores, porque recibían a un bebé de pocos días, seis meses a lo sumo y excepcionalmente; un bebé casi siempre sano que era de su agrado y que su madre no podría reclamar porque habían renunciado a ellos o los habían “abandonado”. Por el otro, para las asistentes sociales, porque entregaban al niño a un matrimonio al que tenían muchas chances de escoger y, al igual que ellos, al resguardo de que sus arbitrios pudieran ser "importunados” por futuras objeciones o arrepentimientos maternos. Tenían entre manos, además, presentaciones a las autoridades judiciales de entregas en las que éstas confiaban, tanto, que lo más común era que consumaran sus legitimaciones legales en un único episodio, sin considerar necesario realizar acciones tendientes ni a la presentación de los progenitores ni al conocimiento de las condiciones en que los niños eran recibidos por sus nuevas familias.

El foco puesto en las modalidades asumidas por la intervención de las maternidades en el arbitrio de adopciones nos revela que el ordenamiento jurídico había depositado en la esfera judicial la potestad de otorgar la última palabra respecto de lo que sería considerado una entrega legítima, pero era una esfera creada y posicionada como el último eslabón de una cadena de instituciones que la precedían, no sólo en términos temporales, sino también en las condiciones efectivas de gestión de las entregas. En una época en que la adopción era una figura jurídica reciente y no existían procedimientos judiciales específicos, el mundo familiar y el mundo estatal compartían en similares proporciones el arbitrio de una entrega en adopción, siendo la esfera judicial una instancia de legalización de actos tramados fuera de sus despachos, a partir de un conjunto rutinario de acciones cuya diversidad dependía, ante todo, de la previa intervención de otras esferas estatales. La forma asumida por la intervención judicial en las ocasiones en que intervenían las maternidades ponía de relieve que el uso discrecional que ellas hacían de los instrumentos procesales respondía en parte a la consideración que merecían las instituciones de las cuales provenían los niños. Así, las maternidades públicas contaban con un particular grado de libertad respecto de la definición de los criterios de entrega. Un camino hacia la adopción marcado por la preferencia del mundo adulto de niños muy pequeños y ajenos al entorno familiar, y cifrado por la opaca y desvirtuada asociación entre adopción y abandono, entre adopción y ascenso social. Una libertad de arbitrio que era sinónimo de una actitud prescindente por parte de las autoridades judiciales, que preferían volcar sus recursos y energías procesales hacia aquellas experiencias de entrega que estaban en manos del mundo familiar. En este tramo de la institucionalización de la adopción en el que distintas esferas compartían el poder de fraguar esos destinos infantiles -en el que tenía lugar una primera y tenue iniciativa de centralización en manos del ámbito administrativo de la minoridad-, los juzgados de menores se granjeaban un espacio en ese entramado de relaciones preexistentes que hacían de la descentralización de las entregas uno de los rasgos emblemáticos del período. Conseguir el ejercicio efectivo de ese poder supuso lograr que las familias y el resto de las instituciones estatales canalizaran hacia él la convalidación de aquello que ya consumaban en la práctica. Para ello, negociaron con el mundo familiar y las instituciones los criterios de lo admisible y de lo inadmisible en relación con las condiciones de entrega y acogida de los niños. Esta negociación entre pautas ejemplares y condiciones de posibilidad estaba signada por el imperativo de que una crianza en familia era preferible a una institucional, y por la existencia de una jerarquía de la confianza depositada por la esfera judicial en las diversas esferas que arbitraban la adopción de niños. 


\section{Notas}

1 Para un análisis histórico de la constitución del fuero provincial de menores y las políticas de minoridad de la primera mitad del siglo XX, ver Gentili (2015).

2 Para conocer el proceso de constitución del fondo y sus características, ver Lugones y Rufer (2004).

$\underline{3}$ Las 85 solicitudes en estudio fueron identificadas a partir de un relevamiento del $65 \%$ de los expedientes contenidos en el fondo, 1.112 ejemplares de los 1.700 que aproximadamente se albergarían de la secretaría a cargo de las guardas.

4 Retomo la noción de narrativa judicial propuesta por Vianna en su análisis antropológico de procesos de guarda tramitados en Río de Janeiro a fines del siglo XX, que ponen de relieve la importancia de "reflexionar sobre cómo ese material específico no sólo 'esconde' u omite datos, sino también produce la posibilidad de ciertos desenlaces, a partir de esas mismas omisiones y del peso burocrático que tienen los dichos convertidos en declaraciones y los peritajes de los especialistas” (2010, p. 23).

$\underline{5}$ Artículo $17^{\circ}$, Ley provincial $N^{\circ} 6.986$ de 1957, “Aplicación del régimen penal y correccional de los menores de 18 años”; y artículo $16^{\circ}$ del Estatuto de la minoridad, Ley provincial $\mathrm{N}^{\circ} 4.873$ de 1966.

6 Archivo General de los Tribunales de Córdoba (AGTC), Centro de Documentación Histórica (CDH), Fondo Menores (FM), caja 19, expediente 24. El nombre de la niña es ficticio, aclaración que vale para todos los nombres que aquí aparecieren, salvo cuando se menciona a funcionarios y empleados públicos.

7 AGTC, CDH, FM, C19, E67.

$\underline{8}$ Las fuentes en estudio no permiten conocer la composición de los servicios sociales de las maternidades, lo que ameritaría una investigación específica. Lo que sí sabemos es que en esos años se trataba de un campo de intervención escasamente profesionalizado que contaba con una singular cuota de aprendizaje práctico no formal (ver Gentili, 2016a).

$\underline{9}$ AGTC, CDH, FM, C16, E2 y 4.

10 Para dar cuenta de la diferencia existente entre ambos tipos de resoluciones (autos interlocutorios y decretos) es importante reconocer algunas de sus características. Los autos interlocutorios son resoluciones de la misma envergadura que las sentencias, en la medida en que a ambos tipos de resoluciones se arriba tras la cumplimentación de los pasos procesales previstos por la legislación (ambas son conservadas de manera permanente en el Archivo de Tribunales). Pero, a diferencia de las sentencias, que tienen carácter irrevocable, los autos interlocutorios no requieren del inicio de un nuevo proceso judicial para revertir sus decisiones; tratándose de una guarda, sólo basta que los guardadores del niño desistan para que se anule el cargo conferido. Los decretos, por su parte, son resoluciones que "no requieren otras formalidades que su expresión por escrito, indicación de lugar y fecha, y la firma del juez” (art. 117, Código Procesal Civil), y se usan, por ejemplo, al ordenarse el pedido de un informe, la realización de una audiencia o la intervención de un asesor de menores. 
11 La suficiencia de una guarda provisoria por decreto para iniciar el juicio de adopción era una práctica vigente entre 1975 y 1983, como constatáramos en el marco del proyecto Derecho a la identidad y adopciones en Córdoba durante la última dictadura, en el que se relevaron las sentencias de adopción de los juzgados civiles y de menores, y los autos de guarda de este último fuero, junto a más de trescientos expedientes de guarda y adopción; informe final con título homónimo al proyecto, inédito (disponible en la Biblioteca del Archivo Provincial de la Memoria).

\section{AGTC, CDH, FM, C16, E4.}

$\underline{13}$ Por razones de espacio no es posible detenernos en esta diversidad de procedimientos, a la que atendí de manera particular en mi tesis doctoral (Gentili, 2016b), en un artículo abocado a las configuraciones familiares a las que eran incorporados los niños (Gentili, 2016a) y en otro en el que, al reconstruir los orígenes familiares de los niños, me concentro en las acciones y omisiones de los servicios sociales de las distintas instituciones y de las autoridades judiciales ante la citación o no de los progenitores (Gentili, 2017).

14 AGTC, CDH, FM, C5, E1.

15 AGTC, CDH, FM, C10, E7.

16 AGTC, CDH, FM, C21, E65.

17 AGTC, CDH, FM, C22, E8.

18 AGTC, CDH, FM, C10, E12.

19 AGTC, CDH, FM, C5, E11; C20, E2 у C21, E3.

20 AGTC, CDH, FM, C6, E44.

21 AGTC, CDH, FM, C18, E26.

$\underline{22}$ AGTC, CDH, FM, C19, E69.

$\underline{23}$ AGTC, CDH, FM, C4, E2; C5, E2; C6, E44; C19, E14, 27, 41, 52, 67 y 69; C20, E2; C23, E14 y C24, E57.

24 Según la asistente social de la Dirección General de Menores que en 1974 entrevistó a la guardadora de un bebé recién nacido en la Maternidad Nacional, la mujer le habría contado que "de común acuerdo con su esposo se inscribieron en el Registro de la Maternidad Nacional, con el fin de adoptar a un niño, y luego de esperar un largo tiempo se vieron recompensados”; AGTC, CDH, FM, C21, E3.

$\underline{25}$ Procesos en que los certificados de los guardadores tienen fechas anteriores a los nacimientos de los niños: AGTC, CDH, FM, C5, E1; C16, E4; C18, E2; C19, E29 y 56; y C21, E3.

$\underline{26}$ En sólo uno de los siete procesos en los que las maternidades informaban que las madres habían abandonado la institución dejando a sus hijos, se registran actuaciones judiciales tendientes a su localización. AGTC, CDH, FM, C16, E2 (con tales actuaciones) y E4; C18, E24; C19, E24, 29 y 41; y C22, C8. 
27 La reconstrucción de las razones que llevaban a las progenitoras -principales protagonistas de estas experiencias- a entregar a sus hijos en adopción, es un aspecto que excede el espacio y los propósitos de este escrito. Sobre el particular, ver Gentili, 2017.

28 Procesos en los que constan renuncias de las progenitoras junto a comunicaciones de las maternidades en las que se decía que los niños habían sido abandonados: AGTC, CDH, FM, C4, E2; C18, E13; C19, E24, 27, 52, 56 y 67; y C23, E14.

$\underline{29}$ Para un análisis de la sanción de la Ley de Patronato de 1919, ver Zapiola (2010), entre otros.

30 Artículo 21 de la Ley de Patronato de Menores de 1919, Código Civil (con las notas de Vélez Sarsfield) y leyes complementarias, Lajouane Editores, Buenos Aires, 1956, pág. 835.

31 Archivo Provincial de la Memoria (APM), Fondo Secretaría de Estado de la Mujer, Niñez, Adolescencia y Familia (FSEMNAF); caja 5, Libro de Actas, reunión del 13/7/73, fs. 52-54.

$\underline{32}$ Para un análisis pormenorizado de la inscripción social de las familias adoptivas y la relación de esas configuraciones familiares diversas con los escenarios en que habían tenido lugar los actos de entrega y acogimiento de los niños, ver Gentili (2016a).

33 La Dirección General de Menores había sido creada en 1945 como repartición a cargo de la política de minoridad de la provincia, teniendo entre sus principales funciones la centralización de la labor de los establecimientos públicos y privados de acogida y reclusión infantil. En 1957 pasó a ser el órgano de colaboración, asistencia técnica y ejecución de los juzgados de menores; ver Gentili, 2015.

34 Archivo de Gobierno (AG), Minoridad, Serie B, T47, 1972, Res. 4.826, 24/10/76 y Res. 4.879, 8/11/72.

35 APM, FSEMNAF, caja 5, Libro de Actas, reuniones del 25/6/73, pp. 48 y 49; 13/7/73, pp. 52-54; 27/9/73, pp. 68-70; 5/12/73, pp. 78 у 79; 31/1/74, pp. 86-88; 20/2/74, pp. 88 y 89; 22/5/74, pp. 9596 у 28/5/74, pp. 97-98.

36 APM, FSEMNAF, caja 5, Libro de Actas, reuniones del 25/6/72, pp. 48 y 49; 5/9/74, pág. 107, y 18/9/74, pág. 111.

37 APM, FSEMNAF, caja 5, Libro de Actas, reunión del 26/12/74, pp. 113-121.

\section{Bibliografía}

Biernat, C., y Ramacciotti, K. (2008). La tutela estatal de la madre y el niño en la Argentina: estructuras administrativas, legislación y cuadros técnicos (1936-1955). Histórica, Ciências, Saúde, 15(2), 331-351.

Billorou, M. J. (2007). Madres y médicos en torno a la cuna: Ideas y prácticas sobre el cuidado infantil (Buenos Aires, 1930-1945). La aljaba, 11, 167-192. 
Cicerchia, R. (1994). Familia: la historia de una idea. Los desórdenes domésticos de la plebe urbana porteña, Buenos Aires, 1776-1850. En C. Wainerman (Ed.), Vivir en familia (pp. 49-72). Buenos Aires: UNICEF y Losada.

Cosse, I. (2006). Estigmas de nacimiento: peronismo y orden familiar, 1946-1955. Buenos Aires: Fondo de Cultura Económica y Universidad San Andrés.

Cosse, I. (2007). Ilegitimidades de origen y vulnerabilidad en la Argentina de mediados del siglo XX. Nuevo Mundo Mundos Nuevos. https://doi.org/10.4000/nuevomundo.12502

Cosse I. (2009). La historia de la familia en la Argentina del siglo XX: nuevas perspectivas de un campo en construcción”. Anuario IEHS, 23, 343-355.

Cosse, I. (2010). Pareja, sexualidad y familia en los años sesenta. Buenos Aires: Siglo XXI.

Cosse, I., Llobet, V., Villalta, C., y Zapiola, M. (2012). Introducción. En I. Cosse, V. Llobet, C. Villalta y M. Zapiola (eds.), Infancias: políticas y saberes en Argentina y Brasil, siglos XIX y XX (11-28).Buenos Aires:Teseo.

Di Liscia, M. S. (2002). Hijos sanos y legítimos: sobre matrimonio y asistencia social en Argentina (1935-1948). Histórica, Ciências, Saúde, 9, 209-232.

Bjerg, M., y Boixadós, R. (2004). Tendencias en la historia de la familia en Argentina. En M. Bjerg y R. Boixadós (eds.), La familia campo de investigación interdisciplinario. Teorías, métodos y fuentes (171-186). Quilmes: Universidad Nacional de Quilmes.

Elias, N. (1998). La civilización de los padres y otros escritos. Colombia: Norma.

Farge, A. (1991). La Atracción del archivo. Edicions Alfons el Magnànim. Institució Valenciana d'Estudis i Investigació.

Farge, A., y Revel, J. (1998). Lógica de las multitudes. Rosario: Homo Sapiens Ediciones.

Flores, M. E. (2004). Expósitos y abandonados. La práctica social de colocación de niños. La Casa Cuna de Córdoba, 1884-1950. Córdoba: Universitas.

Gentili, A. (2015). Un fuero híbrido. Juzgados de menores, precedentes y prácticas en Córdoba, Argentina, primera mitad del siglo XX. Derecho privado y modernización: América Latina y Europa en la primera mitad del siglo XX, 2, 226-241.

Gentili, A. (2016a). Entre anhelos normativos y prácticas consuetudinarias. La conformación de las familias adoptivas en la Córdoba de los años sesenta. Res Gesta, 52.

Gentili, A. (2016b). Pequeños cuerpos. Familias, adopciones y justicia en Córdoba, 1957-1974 (Tesis doctoral en Historia). FFyH, UNC, Córdoba.

Gentili, A. (2017). Relatos judiciales, Estado y sociedad: orígenes familiares de niños adoptados en Córdoba en los sesenta. Población \& Sociedad, 24(2), en prensa.

Gesteira, S. (2013). Buscando el origen. Sentidos sobre la filiación y el parentesco en la organización Raíz Natal "Por el Derecho a la Identidad Biológica" (Tesis de maestría en Antropología Social). FFyL, UBA, Buenos Aires. 
Ghirardi, M. (2008). Reclamados, embargados, cobrados y cedidos. La niñez como ¿valor de uso? en Córdoba, Argentina, siglos XVII y XVIII. En M. Ghirardi (Ed.), Familias iberoamericanas ayer y hoy. Una mirada interdisciplinaria (251-283). Río de Janeiro: Asociación Latinoamericana de Población.

Guy, D. (inédito). From Property Rights to Children’s Rights: Adoption in Argentina, 1870-1948.

Lugones, M. G. (2004). Uma «visita» aos «expedientes»: os processos judiciais referentes aos menores, Córdoba, Argentina, na metade do século XX (Disertación de maestría). Programa de Posgrado en Maestría Social, Museo Nacional, Universidad Federal de Río de Janeiro, Río de Janeiro.

Lugones, M. G., y Rufer, M. (2004). Fuentes en extinción: estudio cualitativo de procesos judiciales de los Tribunales de Menores de Córdoba. Miradas alternativas. Análisis multidisciplinario del fenómeno jurídico, 2, 37-44.

Míguez, E. (2006). Familias de clase media: la formación de un modelo. En F. Devoto y M. Madero (Eds.), Historia de la vida privada en la Argentina. La Argentina plural: 1870-1930 (tercera, Vol. II, pp. 21-45). Buenos Aires: Taurus.

Moreno, J. L. (2004). Historia de la familia en el Río de la Plata. Buenos Aires: Sudamericana.

Nari, M. (2004). Políticas de maternidad y maternalismo político: Buenos Aires, 1890-1940. Buenos Aires: Biblos.

Premo, B. (2008). How Latina America's History of Childhood Came of Age. The Journal of the History of Childhood and Youth, 1(1), 63-76.

Seoane, M. I. (1989a). Un capítulo de la historia de la adopción en el derecho argentino (18171947). Revista de Historia del Derecho, 17, 288-349.

Seoane, M. I. (1989b). Un expediente sobre adopción de 1787-1788. Revista de Historia del Derecho, 9, 427-439.

Seoane, M. I. (1990). Crianza y adopción en el derecho argentino precodificado (1810-1870). Revista de Historia del Derecho, 18, 355-429.

Twinam, A. (2009). Vidas públicas, secretos privados. Género, honor, sexualidad e ilegitimidad en la Hispanoamérica colonial. Buenos Aires: Fondo de Cultura Economica.

Vianna, A. (2010). Derechos, moralidades y desigualdades. Consideraciones acerca de procesos de guarda de niños. En C. Villalta (Ed.), Infancia, justicia y derechos humanos (pp. 21-72). Bernal: Universidad Nacional de Quilmes.

Villalta, C. (2010). Imitar a la naturaleza. La adopción de niños en los años '60: entre ficciones legales y prácticas consuetudinarias. En I. Cosse, K. Felitti, y V. Manzano (Eds.), Los '60 de otra manera. Vida cotidiana, género y sexualidades en la Argentina (pp. 89-129). Buenos Aires: Prometeo.

Villalta, C. (2012). Entregas y secuestros. El rol del Estado en la apropiación de niños. Buenos Aires: Ad Hoc y CELS. 
Williams, R. (2009). Marxismo y literatura. Buenos Aires: Las Cuarenta.

Zapiola, M. C. (2010). La Ley de Patronato de Menores de 1919. ¿Una bisagra histórica? En L. Lionetti y D. Míguez (Eds.), Las infancias en la historia argentina. Intersecciones entre prácticas, discursos e instituciones (1890-1960) (pp. 117-132). Rosario: Prohistoria. 